\title{
Intention to Receive a COVID-19 Vaccine by HIV Status Among a Population-Based Sample of Women and Gender Diverse Individuals in British Columbia, Canada
}

\author{
Angela Kaida ${ }^{1,2}$ - Lori A. Brotto ${ }^{2,3} \cdot$ Melanie C. M. Murray ${ }^{2,3,4} \cdot$ Hélène C. F. Côtéé, ${ }^{2,3}$ - Arianne Y. Albert ${ }^{2}$. \\ Valerie Nicholson ${ }^{1,5} \cdot$ Rebecca Gormley $^{1,5} \cdot$ Shanlea Gordon ${ }^{2} \cdot$ Amy Booth $^{2,3} \cdot$ Laurie W. Smith $^{2,6} \cdot$ Ally Baaske $^{2}$. \\ Liisa A. M. Galea ${ }^{2,3} \cdot$ Manish Sadarangani $^{3,7} \cdot$ Gina S. Ogilvie $^{2,3,8}$
}

Accepted: 31 December 2021 / Published online: 12 January 2022

(c) The Author(s), under exclusive licence to Springer Science+Business Media, LLC, part of Springer Nature 2022

\begin{abstract}
COVID-19 vaccination is recommended for people living with HIV (PLWH), among whom social inequities and co-morbidities may drive risks of COVID-19 infection and outcome severity. Among a provincial (British Columbia) sample, we determined the prevalence of COVID-19 vaccine intention by HIV status and assessed socio-demographic, vaccine hesitancy, and psychological predictors of vaccine intention. Individuals (25-69 years) recruited from province-wide research cohorts and the general public completed an online survey examining COVID-19 impacts (August/2020-March/2021). In an analysis restricted to women and gender diverse participants $(n=5588)$, we compared intention to receive a recommended COVID19 vaccine (Very likely/Likely vs Neutral/Unlikely/Very Unlikely) by self-reported HIV status. Logistic regression models assessed the independent effect of HIV status and other factors on COVID-19 vaccine intention. Of 5588 participants, 69 (1.2\%) were living with HIV, of whom $79.7 \%$ were on antiretroviral therapy. In bivariate analyses, intention to vaccinate was significantly lower among PLWH compared to participants not living with HIV (65.2\% vs 79.6\%; OR 0.44; 95\%CI 0.32-0.60). However, this association was not statistically significant after adjustment for ethnicity, income, education, and essential worker status (aOR 0.85; 95\%CI 0.48-1.55). Among PLWH, those with greater vaccine confidence, positive attitudes towards the COVID-19 vaccine, and more strongly influenced by direct and indirect social norms to vaccinate had significantly higher odds of vaccine intention. Tailored messaging is needed to build vaccine confidence, address questions about vaccine benefits, and support informed vaccination decision-making to promote COVID-19 vaccine uptake among women and gender diverse people living with HIV.
\end{abstract}

Keywords HIV · Women · Intention to vaccinate $\cdot$ Social determinants of health $\cdot$ Gender diverse populations $\cdot$ COVID-19 vaccine $\cdot$ Vaccine hesitancy

Angela Kaida

kangela@sfu.ca

1 Faculty of Health Sciences, Simon Fraser University (SFU), Burnaby, BC, Canada

2 Women's Health Research Institute (WHRI), Vancouver, BC, Canada

3 University of British Columbia (UBC), Vancouver, BC, Canada

4 Oak Tree Clinic, BC Women's Hospital and Health Centre, Vancouver, BC, Canada
5 BC Centre for Excellence in HIV/AIDS, Vancouver, BC, Canada

6 Cancer Control Research, BC Cancer, Vancouver, BC, Canada

7 Vaccine Evaluation Center, BC Children's Hospital Research Institute, Vancouver, BC, Canada

8 British Columbia Centre for Disease Control, Vancouver, BC, Canada 


\section{Introduction}

The COVID-19 pandemic and the associated public health response has significantly disrupted lives and livelihoods in Canada and around the world. As of July 26th 2021 in Canada, 1,427,342 COVID-19 cases and 26,553 related deaths have been reported. Sex-disaggregated data reveal that $50.3 \%$ of COVID-19 cases and $49.8 \%$ of deaths are among females [1], with disproportionate impacts among individuals and communities confronting socio-structural inequities, including poverty, racism, and gender inequity [2-4].

Early in the pandemic, the US Centres for Disease Control and Prevention flagged that people living with HIV (PLWH) may be at heightened risk of severe COVID-19 illness [5]. Emerging data suggest, however, that HIV infection itself does not confer higher susceptibility to COVID-19, [6-8] rather, HIV-accompanying social disparities and co-morbidities may drive observed increases in the risk of infection and outcome severity among PLWH $[9,10]$. This distinction is important as it informs government and public health officials on how best to act to reduce inequities.

The National Advisory Committee on Immunization (NACI) in Canada considered such social disparities and co-morbidities, alongside considerations of risks for SARS-CoV-2 infection and severe illness, to identify priority populations for the first phase of COVID-19 vaccination [11]. Early recommendations prioritized COVID19 vaccination for the following key populations: those at high risk of severe illness and death from COVID-19 (advanced age and/or living with other high-risk conditions), those most likely to transmit COVID-19 to those at high risk and workers essential to maintaining the COVID-19 response (e.g., healthcare workers, caregivers at long-term care facilities), other essential workers outside of healthcare (e.g., police, firefighters, grocery store workers), and those living or working conditions put them at elevated risk or consequence of COVID-19 infection, including Indigenous communities [11]. People living with HIV were not prioritized for early vaccination, unless individuals met other priority population criteria. Canada launched its COVID-19 vaccine roll-out in December 2020 for adults, with eligibility expanding to include all individuals $12+$ years of age (without contraindications) by June 2021 [12].

Although relatively few PLWH participated in COVID19 vaccine trials, available data indicate that the vaccines are effective and that there are no unusual safety concerns among people with well-controlled HIV, including those with undetectable viral loads and CD4 cell counts above 200 cells $/ \mathrm{mm}^{3}[13,14]$. As such, the NACI strongly recommended that immunosuppressed and immunocompromised individuals (including PLWH) be offered a complete COVID-19 vaccine series [11]. In tandem, the British Columbia Centre for Excellence in HIV/AIDS (BCCfE) Committee for Drug Evaluation and Therapy similarly advised that "People living with HIV (PLWH) aged 18 years or older should be vaccinated for COVID19 if they meet current public health criteria for priority groups and if they have no contraindications... regardless of CD4 count", and recommended receipt of any of the COVID-19 vaccines currently approved in Canada (i.e., Pfizer-BioNTech, Moderna, AstraZeneca, and Janssen vaccines) [15].

Adherence to these recommendations and the ultimate success of the national COVID-19 vaccine roll-out is contingent on vaccine intention and vaccine uptake. Vaccine hesitancy (a concept defined as the refusal or delay in accepting vaccination despite the availability of vaccination services $[16,17])$, vaccine misinformation, and medical mistrust may limit vaccine uptake and contribute to further perpetuating COVID-19 inequities [18-20]. There are currently few data regarding intention to receive the COVID-19 vaccine among PLWH [18, 21], and, to our knowledge, no data from women or gender diverse individuals living with HIV. Moreover, there is a paucity of data examining vaccine hesitancy or the attitudes, social norms, and perceived behavioral controls that predict COVID-19 vaccine intention among PLWH, and whether these differ from patterns in the general population. In Canada, such data are particularly pertinent since women living with HIV (WLWH) experience significant sociostructural inequities and co-morbidities relative to both men living with HIV and HIV-negative women. For instance, among WLWH, 79\% are Indigenous, Black, or other women of colour, including 36\% who are of Indigenous ancestry [22]; 70\% live below the poverty line (defined as \$20 K CAD per year) [23]; and 75\% live with one or more co-morbidities in additional to HIV, including cardiovascular disease, cancers, osteoporosis, chronic kidney or liver disease, chronic depression, anxiety and other mental health illnesses [24, 25]. WLWH also have poorer HIV clinical outcomes across the HIV care cascade including lower prevalence of antiretroviral therapy (ART) initiation and HIV viral suppression compared with men [26]; all factors known to increase risk and consequence of SARS-CoV-2 infection.

Using population-based survey data from a provincial sample of women and gender diverse individuals in British Columbia (BC), Canada, the objectives of this study were (1) to estimate and compare intention to receive the COVID19 vaccine by HIV status; (2) to measure and compare the prevalence of vaccine hesitancy [17, 27] by HIV status; (3) to measure and compare the prevalence of four COVID-19 vaccine-specific psychological constructs grounded in the Theory of Planned Behavior [28] by HIV status, including 
vaccine attitudes, perceived behavioral control to receive the COVID-19 vaccine if desired, and the influence of direct and indirect social norms; and (4) among those living with HIV, to examine whether vaccine hesitancy and psychological constructs predict COVID-19 vaccine intention.

These analyses are aimed at guiding public health programming and recommendations for COVID-19 vaccination for women and gender diverse individuals living with HIV to optimize COVID-19 vaccine uptake in this population.

\section{Methods}

\section{Study Design and Participants}

We used cross-sectional survey data from participants enrolled in the Rapid Evidence Study of a Provincial Population Based COhort for GeNder and SEx (RESPPONSE) study, which assessed the impacts of COVID-19 and the associated public health control measures on people across the Canadian province of BC [29].

Individuals (aged 25-69 years, BC residents) enrolled in existing, large provincially-representative community and hospital-based cohort studies who had consented to be contacted for future research were invited to complete an online survey examining impacts of COVID-19 (August 20-March $1,2021)$ and receive an at-home SARS-CoV-2 research antibody test (results to be reported elsewhere). Two existing cohorts (the Canadian HIV Women's Sexual and Reproductive Health cohort study (CHIWOS) [30] and the Children and Women: AntiRetroviral Therapy and Markers of Aging (CARMA) study [24] specifically enrolled WLWH while other cohorts enrolled members of the general population, inclusive to all people living with HIV.

All eligible individuals were sent an email invitation to participate in an online survey. To increase sex and gender diversity of the study, upon completing the survey, participants were asked to provide the email address of an adult household member who identified as another gender. These individuals were then invited to participate. All prospective participants who did not complete the survey after the initial invitation were sent up to two email reminders, each seven days apart. Participants who did not complete the survey within 21 days after the initial invitation were considered as having declined participation.

For power considerations, we aimed to enroll a total of $n=750$ participants per each 5-year age-strata [20]. After recruiting from the existing cohorts, we pursued public recruitment via social media, websites, listservs, and word-of-mouth to fill the target quota for individuals aged 25-40 and 65-69 years. We employed additional targeted recruitment strategies to enhance study participation among WLWH (of all eligible ages), who are consistently under-represented in research [31, 32]. Learning from community-based research principles [33, 34], we hired and trained three experienced Peer Research Associates (WLWH trained in quantitative research methods) [35] to support recruitment of WLWH, who may not have had a working email address, reliable access to computers, internet access, or other infrastructure required to complete an online survey. We also pursued recruitment of WLWH via researchers, HIV clinics, and community-based organizations who support PLWH in BC.

\section{Ethical Considerations}

All participants provided voluntary informed consent at enrollment. After completing the survey, participants were entered into a lottery to receive a $\$ 100$ gift card. Ethical approval was received from The University of British Columbia Research Ethics Board (H20-01421).

\section{Inclusion and Exclusion Criteria}

Analyses were restricted to self-identified women (inclusive to cis and trans women) and gender diverse participants either living with or not living with HIV. Gender diverse individuals comprised $1.2 \%$ of the overall sample [20], however, given a high proportion of gender diverse individuals living with HIV who identified a biological sex of female, we chose to include this group in the analysis to enable consideration of this priority and underserved group living with HIV.

\section{Study Procedures}

Participants completed a structured online questionnaire (supported by Research Electronic Data Capture (REDCap)) software [36]. The questionnaire was developed by experts in sex-and-gender based analysis, vaccine intention, Theory of Planned Behavior, social determinants of health, economics, mental health, and sexual and reproductive health, using validated scales when available. The questionnaire was assessed for face validity and comprehension, pilot tested, revised, and the final version was implemented using REDCap. Questionnaires were available in English and took a median of $31 \mathrm{~min}$ [Interquartile range [IQR] 23-47] to complete.

\section{Measures}

The primary outcome was 'intention to vaccinate', considered as the most proximate measure to actual vaccine uptake, and assessed via a 5-point Likert scale to the question "If $a$ COVID-19 vaccine were to become available to the public, and recommended for you, how likely are you to receive it?" 
The question was phrased theoretically given that a large majority of participants completed the survey before the COVID-19 vaccine was widely available in BC. Consistent with a RESPPONSE study analysis of overall vaccine intentions in $\mathrm{BC}$, responses were dichotomized as follows: Participants who reported "Very Likely" or "Somewhat Likely" were considered as having an intention to vaccinate while those who reported "Neutral", "Unlikely", or "Very Unlikely" were considered as not intending to vaccinate [20].

Potential socio-demographic correlates of vaccine intention were considered a priori, including: age, sex, gender (woman or gender diverse, which referred to individuals who identify as, but not limited to, gender non-binary, GenderQueer, Two-Spirit, agender, gender fluid, gender nonconforming, or other gender identity), Indigenous ancestry, ethnicity [37], education, annual household income, existing chronic health conditions (excluding HIV), and employment as an essential worker including both healthcare and non-healthcare essential workers (defined as those working in retail, transportation, social services, and other services deemed essential), [38] all assessed by self-report.

Among PLWH, we measured median time living with HIV (median [IQR]), the proportion on ART, with an undetectable HIV viral load $(<50$ copies/mL), receipt of HIV medical care since the COVID-19 restrictions were implemented in mid-March 2020, and how much their HIV status affected their fear of acquiring COVID-19 (more/much more fearful $v s$ no difference $v s$ less/much less fearful).

\section{WHO Vaccine Hesitancy Scales and Psychological Constructs Within the Theory of Planned Behavior}

The questionnaire assessed several psychological constructs as potential correlates of vaccine intention, including (1) a modified WHO Vaccine Hesitancy Scale [17, 27], which included two factors: Lack of Vaccine Confidence (7-item 5-point Likert scale from Strongly Agree to Strongly Disagree, with higher agreement corresponding with higher lack of general vaccine confidence) and Vaccine Risk (2-item 5-point Likert scale from Strongly Agree to Strongly Disagree, with higher agreement corresponding with higher concerns about vaccine risks); and grounded in the Theory of Planned Behavior [28], items developed and previously used to measure key factors shown to influence COVID19 vaccine intention [20] including (2) Attitudes towards the COVID-19 vaccine (8 item 5-point Likert scale from Strongly Agree to Strongly Disagree, with higher agreement corresponding with more positive attitudes towards the COVID-19 vaccine); (3) Perceived Behavioral Control to receive a COVID-19 vaccine (4 item 5-point Likert scale from Strongly Agree to Strongly Disagree, with higher agreement corresponding with higher self-perception of being able to receive the COVID-19 vaccine if desired); (4) the influence of Direct Social Norms (4-item 5-point Likert scale from Strongly Agree to Strongly Disagree, with higher agreement corresponding with being more likely to be influenced by direct social norms to receive the COVID19 vaccine); and (5) the influence of Indirect Social Norms (8 item 5-point Likert scale assessing both whether various influencers would Strongly Approve to Strongly Disapprove of the participant receiving the COVID-19 vaccine and how much the participant Strongly Agrees to Strongly Disagrees that what the influencer thinks is important to them, with higher scores indicating a greater influence of indirect social norms). All scale items are shown in Table 4.

\section{Data Analyses}

Descriptive statistics (mean (Standard Deviation $( \pm \mathrm{SD})$ ) or median [IQR] for continuous variables and $\mathrm{n}(\%)$ for categorical variables) were used to characterize baseline distributions of study variables, stratified by HIV status. Baseline differences were compared using Wilcoxon rank sum test for continuous variables and Fisher's exact test for categorical variables.

Descriptive statistics were also used to report the prevalence of intention to vaccinate by HIV status. Bivariable analyses examined the relationship between intention to vaccinate and socio-demographic variables. An exploratory multivariable logistic regression model was used to examine the crude and adjusted odds ratios (with $95 \%$ confidence intervals) between HIV status and vaccine intention controlling for potential socio-demographic confounders. After assessing collinearity, a priori possible predictors of vaccine intention with $\mathrm{p}<0.1$ in bivariable analyses were considered in the multivariable model. Multivariable analyses included only non-missing data.

For each of the items in the WHO Vaccine Hesitancy Scale and the psychological constructs, the proportion of participants reporting Strongly Agree/Agree (vs Neutral/ Disagree/Strongly Disagree) were reported and compared by HIV status, with differences compared using Pearson $\chi^{2}$ or Fisher's exact test. We also computed the mean $( \pm S D)$ total score of each scale and compared means by HIV status using Wilcoxon rank sum tests.

Among PLWH, we used logistic regression to examine associations between socio-demographic characteristics, the WHO Vaccine Hesitancy Scale, and the psychological constructs with COVID-19 vaccine intention.

All p-values were two-sided and considered statistically significant at $\mathrm{p}<0.05$. Analyses were conducted in R v.4.0.2 [39]. 


\section{Results}

Between August 20th, 2020 and March 1st, 2021, 6518 individuals completed the online survey, of whom 5588 (85.7\%) identified as women or gender diverse individuals and were included in this analysis. Of these, $69(1.23 \%)$ were living with HIV (LWH) whereas 5519 (98.8\%) were not LWH.

\section{Baseline Characteristics}

Age was similar among participants LWH (mean \pm SD: $49.9 \pm 11.4$ years $)$ and not LWH $(48.1 \pm 12.1$ years $)$ and a majority reported being assigned female sex at birth (99.6\%). Participants LWH reported significantly greater gender, ethno-racial, and socio-economic diversity. Compared to those not LWH, individuals LWH were significantly more likely to identify as gender diverse $(8.7 \%$ vs $\left.1.2 \% ; X^{2}=23.62 ; \mathrm{p}=0.0003\right)$, of Indigenous ancestry ( $29 \%$ vs $\left.3 \% ; X^{2}=266.69 ; \mathrm{p}<0.001\right)$, African Caribbean or Black $\left(8.7 \%\right.$ vs $\left.0.3 \% ; X^{2}=266.69 ; p<0.0001\right)$, report a household income below $\$ 20,000 /$ year $\left(17.4 \%\right.$ vs $2.3 \%$; $X^{2}=266.69$; $\mathrm{p}<0.0001)$, and a highschool education or less $(34.8 \%$ vs $\left.12.2 \% ; X^{2}=29.54 ; \mathrm{p}<0.0001\right)$. There were no differences by essential worker employment $\left(27.5 \%\right.$ vs $32.9 \% ; X^{2}=2.47$; $\mathrm{p}=0.30)($ Table 1$)$.

A higher proportion of participants LWH reported living with $\geq 1$ chronic health condition (excluding HIV) $(82.6 \%$ vs $49.6 \% ; X^{2}=45.38 ; \mathrm{p}<0.0001$ ) and were significantly more likely to report living with chronic obstructive pulmonary disease (COPD) or emphysema, chronic lung disease, heart disease, liver disease and liver cirrhosis, and renal problems compared with those not LWH.

\section{Characteristics of Participants Living with HIV}

Median years living with HIV was 20.5 [IQR 14-17], $79.7 \%$ were currently on ART for a median of 14.0 years [10-23 years], and $73.9 \%$ reported being virally undetectable ( $<50$ copies $/ \mathrm{mL}$ ). Overall, $62.3 \%$ reported receiving any HIV medical care since the COVID-19 restrictions were implemented and $58.6 \%$ reported that their HIV-positive status made them more fearful of acquiring COVID-19 (3.4\% reported less fearful, $37.9 \%$ reported that it makes no difference) (Table 2).

Table 1 Baseline characteristics of study sample overall and by HIV status, column \% $(n=5588)$

\begin{tabular}{|c|c|c|c|c|c|}
\hline & \multirow{2}{*}{$\begin{array}{l}\text { Total } \\
\mathrm{n}=5588\end{array}$} & \multicolumn{2}{|l|}{ HIV status } & \multirow[b]{2}{*}{ Test statistic } & \multirow[b]{2}{*}{$\mathrm{p}$ value } \\
\hline & & $\begin{array}{l}\text { Not living with HIV } \\
(\mathrm{n}=5519)\end{array}$ & $\begin{array}{l}\text { Living with HIV } \\
(\mathrm{n}=69)\end{array}$ & & \\
\hline Age Mean (SD) & $48.2( \pm 12.1)$ & $48.1( \pm 12.1)$ & $49.9( \pm 11.4)$ & $\mathrm{W}=176592$ & 0.30 \\
\hline \multicolumn{6}{|l|}{$\operatorname{Sex}$} \\
\hline Female & $5565(99.6 \%)$ & $5499(99.6 \%)$ & $66(95.7 \%)$ & $X^{2}=25.34$ & 0.001 \\
\hline Male & $17(0.3 \%)$ & $14(0.3 \%)$ & $3(4.3 \%)$ & & \\
\hline \multicolumn{6}{|l|}{ Gender } \\
\hline Woman & $5,514(98.7 \%)$ & $5,451(98.8 \%)$ & $63(91.3 \%)$ & $X^{2}=23.62$ & 0.0003 \\
\hline $\begin{array}{l}\text { Gender diverse (non-binary, GenderQueer, agender, } \\
\text { Two-spirit, gender fluid, or other gender identity) }\end{array}$ & $74(1.3 \%)$ & $68(1.2 \%)$ & $6(8.7 \%)$ & & \\
\hline Ethnicity & & & & $X^{2}=266.69$ & $<0.0001$ \\
\hline Indigenous & $186(3.3 \%)$ & $166(3.0 \%)$ & $20(29.0 \%)$ & & \\
\hline African/Caribbean/Black & $21(0.4 \%)$ & $15(0.3 \%)$ & $6(8.7 \%)$ & & \\
\hline White & $4,441(79.5 \%)$ & $4,402(79.8 \%)$ & $39(56.5 \%)$ & & \\
\hline Other or mixed ethnicity & $775(13.9 \%)$ & $771(14.0 \%)$ & $4(5.8 \%)$ & & \\
\hline Education More than high school & $4,879(87.3 \%)$ & $4,834(87.6 \%)$ & $45(65.2 \%)$ & $X^{2}=29.54$ & $<0.0001$ \\
\hline Household income $<\$ 20 \mathrm{~K} /$ year & $138(2.5 \%)$ & $126(2.3 \%)$ & $12(17.4 \%)$ & $X^{2}=266.69$ & $<0.0001$ \\
\hline \multicolumn{6}{|l|}{ Chronic health conditions (excluding HIV) } \\
\hline None & $2792(50.0 \%)$ & $2780(50.4 \%)$ & $12(17.4 \%)$ & $X^{2}=45.38$ & $<0.0001$ \\
\hline 1 & $1538(27.5 \%)$ & $1518(27.5 \%)$ & $20(29.0 \%)$ & & \\
\hline $2+$ & $1249(22.4 \%)$ & $1212(22.0 \%)$ & $37(53.6 \%)$ & & \\
\hline \multicolumn{6}{|l|}{ Essential worker } \\
\hline No & $3752(67.1 \%)$ & $3702(67.1 \%)$ & $50(72.5 \%)$ & $X^{2}=2.47$ & 0.30 \\
\hline Yes, health worker & $865(15.5 \%)$ & $859(15.6 \%)$ & $6(8.7 \%)$ & & \\
\hline Yes, other essential worker & $967(17.3 \%)$ & $954(17.3 \%)$ & $13(18.8 \%)$ & & \\
\hline
\end{tabular}


Table 2 Baseline characteristics of people living with HIV enrolled in the RESPPONSE study $(\mathrm{n}=69)$

\begin{tabular}{lll}
\hline Characteristic & $\mathrm{n}$ or Median & $\%$ or IQR \\
\hline Median years living with HIV & 20.5 & $14.0-17.0$ \\
Currently on antiretroviral therapy (ART) & 55 & $79.7 \%$ \\
Median years on ART & 14.0 & $10.0-23.0$ \\
Undetectable HIV viral load (<50 copies/mL) & 51 & $73.9 \%$ \\
Received any HIV medical care since COVID-19 restrictions & 43 & $62.3 \%$ \\
How much does your HIV status affect your fear of acquiring COVID- & \\
$\quad$ 19? (n=58) & 34 & \\
More/much more fearful & 22 & $58.6 \%$ \\
It makes no difference & 2 & $37.9 \%$ \\
Less/much less fearful & & $3.4 \%$ \\
\hline
\end{tabular}

\section{Intention to Receive a COVID-19 Vaccine by HIV Status and Socio-demographic Characteristics}

In the overall sample, $79.7 \%$ reported being "very or somewhat likely" to receive a COVID-19 vaccine if it were to become available to the public and recommended for them. Intention to vaccinate was significantly lower among participants LWH compared with those not LWH (65.2\% vs $79.6 \% ; L R T=6.87 ; \mathrm{p}=0.009$. OR $0.49 ; 95 \%$ CI $0.30-0.83$ ) (Table 3).

In the full sample, intention to vaccinate was also lower among racialized individuals, including people of Indigenous ancestry (65.1\%; OR 0.44; 95\% CI $0.32-0.60)$, African/Caribbean/and Black people (57.1\%; OR 0.32; 95\% CI 0.13-0.78), and people of other or mixed ethnicities (77.8\%; OR 0.83; 95\% CI 0.69-1.00) relative to white participants $(80.9 \%)$. Participants residing in lower income households, with less education, or essential workers not in the health sector were also significantly less likely to report an intention to vaccinate. There were no significant differences by age, gender, or the presence of chronic health conditions.

In the multivariable model, living with HIV was no longer significantly associated with intention to vaccinate (adjusted OR 0.85; 95\%CI 0.48-1.55). The observed effect in unadjusted analyses was attenuated by differences in the distribution of ethnicity, household income, education, and essential worker status between groups. Compared to white participants, people of Indigenous ancestry (aOR 0.49; 95\% CI $0.35-0.70$ ) and people of other or mixed ethnicities (aOR 0.76 ; 95\% CI 0.62-0.94) had significantly lower adjusted odds of reporting an intention to vaccinate. There was no significant difference among African/Caribbean/and Black participants, although the sample was small (OR 0.49; 95\% CI 0.19-1.38). Participants residing in lower income households $(<\$ 40 \mathrm{~K}$ per year aOR $0.53 ; 95 \%$ CI $0.42-0.67$ and $\$ 40 \mathrm{~K}$ to $<\$ 80 \mathrm{~K}$ per year aOR $0.77 ; 95 \%$ CI $0.64-0.92$ compared with those with household incomes of $\geq \$ 80 \mathrm{~K}$ per year), with a high school education or less (aOR 0.65; 95\% CI 0.53-0.79), or who were essential workers not in the health sector (aOR 0.69 ; 95\% CI $0.57-0.83$ ) had significantly lower adjusted odds of reporting an intention to vaccinate.

\section{WHO Vaccine Hesitancy Scale and Psychological Constructs by HIV Status}

All scales demonstrated good to strong agreement (Cronbach's alpha ranging from a low of 0.63 for the Perceived Behavioral Control scale to a high of 0.95 for the WHO Lack of Vaccine Confidence Scale) (Table 4).

Lack of vaccine confidence was low overall, however, participants LWH expressed significantly higher lack of vaccine confidence (or higher vaccine hesitancy) across each of the 7 scale items. Among those LWH, mean Lack of Vaccine Confidence score was $1.6(\mathrm{SD}=1.1)$ compared with 1.3 $(\mathrm{SD}=0.6)$ among those not $\mathrm{LWH}(W=151,584 ; \mathrm{p}=0.005)$.

Perceptions of vaccine risks were high overall $(45 \%$ reported being "concerned about potential serious adverse effects of vaccines"), however, there were no significant differences by HIV status. Among respondents LWH, the mean Vaccine Risk score was 3.0 $(\mathrm{SD}=1.1)$, similar to that among those not LWH (3.0 ( $\mathrm{SD}=1.1)(W=186,332 ; \mathrm{p}=0.82)$.

Attitudes towards the COVID-19 vaccine were positive with at least $75 \%$ Strongly Agreeing/Agreeing with most scale items, with the exception of three items where a lower proportion of participants agreed that a COVID-19 vaccine would be effective at preventing COVID- 19, would be safe, or should be mandatory. Participants LWH expressed significantly less positive attitudes towards the COVID-19 vaccine across each of the 8 scale items, with the exception of "COVID-19 is a serious illness" where agreement was similar $(81.1 \%$ vs $84.2 \%$; $=0.86)$. Among participants LWH, the mean Attitudes towards the COVID-19 vaccine score was $32.5(\mathrm{SD}=6.6)$ compared with $34.5(\mathrm{SD}=5.8)$ among those not LWH $(W=168,099 ; \mathrm{p}=0.004)$.

Approximately two-thirds of participants reported perceiving that they had high behavioral control over whether or not they could receive the COVID-19 vaccine if they 


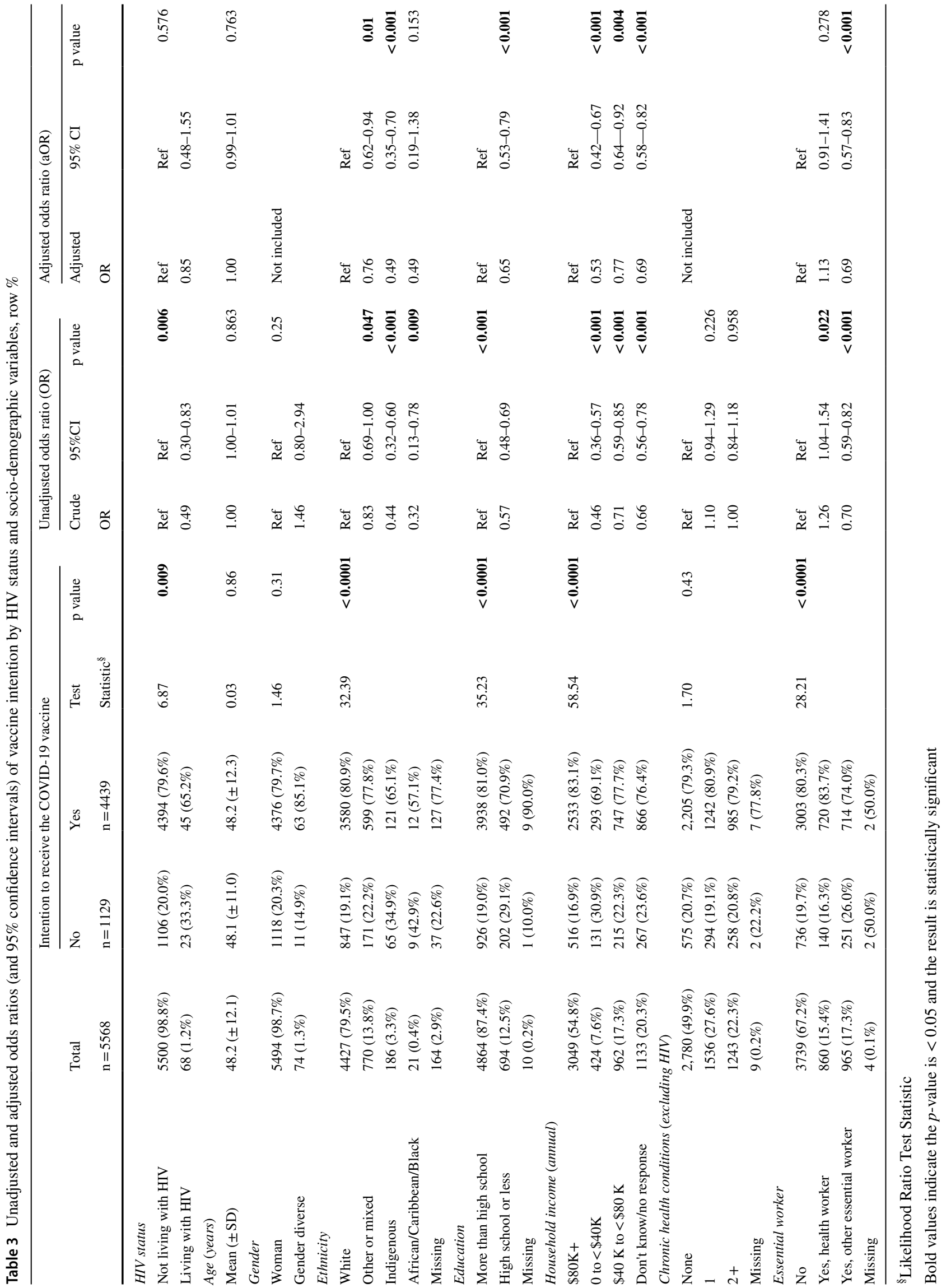


Table 4 Vaccine Hesitancy and COVID-19 vaccine Psychological Constructs by HIV status, column \%

\begin{tabular}{|c|c|c|c|c|c|c|}
\hline & Mean score (SD) overall & $\begin{array}{l}\text { Scale alpha } \\
\text { (standard- } \\
\text { ized) }\end{array}$ & $\begin{array}{l}\text { Not living with HIV } \\
(\mathrm{n}=5519)\end{array}$ & $\begin{array}{l}\text { Living with HIV } \\
(\mathrm{n}=69)\end{array}$ & Test-statistic & $\mathrm{p}$ value \\
\hline $\begin{array}{l}\text { WHO Lack of Vaccine Con- } \\
\text { fidence Scale (range from } \\
1 \text { to 5, with higher scores } \\
\text { indicating higher lack of } \\
\text { confidence) }\end{array}$ & $1.3( \pm 0.6)$ & 0.949 & $1.3( \pm 0.6)$ & $1.6( \pm 1.1)$ & $\mathrm{W}=151,584$ & 0.005 \\
\hline Missing & $40(0.7 \%)$ & & $38(0.7 \%)$ & $2(2.9 \%)$ & & \\
\hline \multicolumn{3}{|l|}{ By item } & \multicolumn{4}{|c|}{ \% reporting strongly disagree/disagree/neutral } \\
\hline \multicolumn{3}{|c|}{ Childhood vaccines are important for a child's health } & $3 \%$ & $12 \%$ & $X^{2}=26.43$ & 0.001 \\
\hline \multicolumn{3}{|c|}{ Getting vaccines is a good way to protect children from disease } & $3 \%$ & $12 \%$ & $X^{2}=28.89$ & 0.0004 \\
\hline \multicolumn{3}{|c|}{$\begin{array}{l}\text { Having a child vaccinated is important for the health of others in my } \\
\text { community }\end{array}$} & $3 \%$ & $13 \%$ & $X^{2}=26.65$ & 0.0003 \\
\hline \multicolumn{3}{|c|}{ Childhood vaccines are effective (VHS 3) } & $3 \%$ & $14 \%$ & $X^{2}=33.32$ & $<0.0001$ \\
\hline \multicolumn{3}{|c|}{$\begin{array}{l}\text { Generally, I do what my doctor or health care provider recommends } \\
\text { about vaccines }\end{array}$} & $8 \%$ & $16 \%$ & $X^{2}=37.67$ & 0.0008 \\
\hline \multicolumn{3}{|c|}{$\begin{array}{l}\text { All childhood vaccines offered by the } \mathrm{BC} \text { immunization program in } \\
\text { my community are beneficial }\end{array}$} & $8 \%$ & $19 \%$ & $X^{2}=29.98$ & $<0.0001$ \\
\hline \multicolumn{3}{|c|}{$\begin{array}{l}\text { The information I receive about vaccines from the vaccination pro- } \\
\text { gram is reliable and trustworthy }\end{array}$} & $12 \%$ & $19 \%$ & $X^{2}=17.20$ & 0.02 \\
\hline & Mean score (SD) overall & $\begin{array}{l}\text { Scale alpha } \\
\text { (standard- } \\
\text { ized) }\end{array}$ & $\begin{array}{l}\text { Not living with HIV } \\
(\mathrm{n}=5519)\end{array}$ & $\begin{array}{l}\text { Living with HIV } \\
(\mathrm{n}=69)\end{array}$ & Test-statistic & $\mathrm{p}$ value \\
\hline $\begin{array}{l}\text { WHO Vaccine Risks Scale } \\
\text { (range from } 1 \text { to 5, with } \\
\text { higher scores indicating } \\
\text { higher concerns about } \\
\text { vaccine risks) }\end{array}$ & $3.0( \pm 1.1)$ & 0.678 & $3.0( \pm 1.1)$ & $3.0( \pm 1.1)$ & $\mathrm{W}=186,332$ & 0.82 \\
\hline Missing & $46(0.8 \%)$ & & $44(0.8 \%)$ & $2(2.9 \%)$ & & \\
\hline \multicolumn{3}{|l|}{ By item } & \multicolumn{4}{|c|}{$\%$ reporting strongly agree/agree } \\
\hline \multicolumn{3}{|c|}{ New vaccines carry more risks than older vaccines } & $37 \%$ & $26 \%$ & $X^{2}=5.76$ & 0.15 \\
\hline \multicolumn{3}{|c|}{ I am concerned about potential serious adverse effects of vaccines } & $45 \%$ & $48 \%$ & $X^{2}=2.06$ & 0.72 \\
\hline & Mean score (SD) overall & $\begin{array}{l}\text { Scale alpha } \\
\text { (standard- } \\
\text { ized) }\end{array}$ & $\begin{array}{l}\text { Not living with HIV } \\
(\mathrm{n}=5519)\end{array}$ & $\begin{array}{l}\text { Living with HIV } \\
(\mathrm{n}=69)\end{array}$ & Test-statistic & $\mathrm{p}$ value \\
\hline $\begin{array}{l}\text { TPB Attitudes towards a } \\
\text { COVID-19 Vaccine Scale } \\
\text { (range from } 8 \text { to } 40, \text { with } \\
\text { higher scores indicating } \\
\text { more positive attitudes } \\
\text { towards the COVID-19 } \\
\text { vaccine) }\end{array}$ & $34.5( \pm 5.8)$ & 0.932 & $34.5( \pm 5.8)$ & $32.5( \pm 6.6)$ & $\mathrm{W}=168,099$ & 0.004 \\
\hline Missing & $702(12.6 \%)$ & & $690(12.5 \%)$ & $12(17.4 \%)$ & & \\
\hline \multicolumn{3}{|l|}{ By item } & \multicolumn{4}{|c|}{$\%$ reporting strongly agree/agree } \\
\hline \multicolumn{3}{|l|}{ COVID-19 is a serious illness } & $84 \%$ & $81 \%$ & $X^{2}=1.19$ & 0.86 \\
\hline \multicolumn{3}{|c|}{$\begin{array}{l}\text { A COVID-19 vaccine would be beneficial for individuals } 60 \text {-years and } \\
\text { older }\end{array}$} & $84 \%$ & $68 \%$ & $X^{2}=34.98$ & 0.0002 \\
\hline \multicolumn{3}{|c|}{$\begin{array}{l}\text { A COVID-19 vaccine would be beneficial for the health of my com- } \\
\text { munity }\end{array}$} & $83 \%$ & $68 \%$ & $X^{2}=18.36$ & 0.006 \\
\hline \multicolumn{3}{|c|}{ A COVID-19 vaccine would be beneficial } & $83 \%$ & $67 \%$ & $X^{2}=20.86$ & 0.003 \\
\hline \multicolumn{3}{|c|}{ A COVID-19 vaccine would be beneficial for children } & $75 \%$ & $61 \%$ & $X^{2}=10.32$ & 0.035 \\
\hline \multicolumn{3}{|c|}{ A COVID-19 vaccine would be effective in preventing COVID-19 } & $68 \%$ & $49 \%$ & $X^{2}=20.32$ & 0.002 \\
\hline \multicolumn{3}{|c|}{ A COVID-19 vaccine would be safe } & $62 \%$ & $45 \%$ & $X^{2}=14.06$ & 0.007 \\
\hline
\end{tabular}


Table 4 (continued)

\begin{tabular}{|c|c|c|c|c|c|c|}
\hline & Mean score (SD) overall & $\begin{array}{l}\text { Scale alpha } \\
\text { (standard- } \\
\text { ized) }\end{array}$ & $\begin{array}{l}\text { Not living with HIV } \\
(\mathrm{n}=5519)\end{array}$ & $\begin{array}{l}\text { Living with HIV } \\
(\mathrm{n}=69)\end{array}$ & Test-statistic & $\mathrm{p}$ value \\
\hline \multirow{2}{*}{$\begin{array}{l}\text { A COVID-19 vaccine } \\
\text { should be mandatory }\end{array}$} & & & $45 \%$ & $35 \%$ & $X^{2}=14.31$ & 0.007 \\
\hline & Mean score (SD) overall & $\begin{array}{l}\text { Scale alpha } \\
\text { (standard- } \\
\text { ized) }\end{array}$ & $\begin{array}{l}\text { Not living with HIV } \\
(\mathrm{n}=5519)\end{array}$ & $\begin{array}{l}\text { Living with HIV } \\
(\mathrm{n}=69)\end{array}$ & Test-statistic & $\mathrm{p}$ value \\
\hline $\begin{array}{l}\text { Perceived Behavioral } \\
\text { Control to receive the } \\
\text { COVID-19 vaccine } \\
\text { Scores ranging from } 1 \text { to } \\
\text { 20, with higher scores } \\
\text { indicating higher levels } \\
\text { of perceived control) }\end{array}$ & $15.9( \pm 2.7)$ & 0.634 & $15.9( \pm 2.7)$ & $16.3( \pm 2.7)$ & $\mathrm{W}=133,702$ & 0.19 \\
\hline Missing & \multicolumn{2}{|l|}{$595(10.6 \%)$} & $586(10.6 \%)$ & $9(13.0 \%)$ & & \\
\hline \multicolumn{3}{|l|}{ By item } & \multicolumn{4}{|c|}{$\%$ reporting strongly agree/agree } \\
\hline \multicolumn{3}{|c|}{$\begin{array}{l}\text { It would be difficult to receive the COVID-19 vaccine (Strongly } \\
\text { Disagree/Disagree) }\end{array}$} & $62 \%$ & $59 \%$ & $X^{2}=4.90$ & 0.26 \\
\hline \multirow{2}{*}{\multicolumn{3}{|c|}{$\begin{array}{l}\text { I could easily receive a COVID-19 vaccine if I wanted to } \\
\text { It would be completely up to me whether I received the COVID-19 } \\
\text { vaccine }\end{array}$}} & $66 \%$ & $61 \%$ & $X^{2}=3.41$ & 0.40 \\
\hline & & & $68 \%$ & $72 \%$ & $X^{2}=9.30$ & 0.075 \\
\hline \multicolumn{3}{|c|}{$\begin{array}{l}\text { How much control do you feel you would have over whether you } \\
\text { receive a COVID-19 vaccine? (A lot/some control) }\end{array}$} & $74 \%$ & $68 \%$ & $X^{2}=13.46$ & 0.011 \\
\hline & Mean score (SD) overall & $\begin{array}{l}\text { Scale alpha } \\
\text { (standard- } \\
\text { ized) }\end{array}$ & $\begin{array}{l}\text { Not living with HIV } \\
(\mathrm{n}=5519)\end{array}$ & $\begin{array}{l}\text { Living with HIV } \\
(\mathrm{n}=69)\end{array}$ & Test-statistic & $\mathrm{p}$ value \\
\hline $\begin{array}{l}\text { Direct social norms (range } \\
\text { from } 1 \text { to } 20 \text { with higher } \\
\text { scores indicating being } \\
\text { more influenced by direct } \\
\text { social norms) }\end{array}$ & $14.7( \pm 3.4)$ & 0.713 & $14.7( \pm 3.3)$ & $12.7( \pm 3.8)$ & $\mathrm{W}=176,932$ & $<0.0001$ \\
\hline Missing & $658(11.8 \%)$ & & $644(11.7 \%)$ & $14(20.3 \%)$ & & \\
\hline \multicolumn{3}{|l|}{ By item } & \multicolumn{4}{|c|}{$\%$ reporting strongly agree/agree } \\
\hline \multicolumn{3}{|c|}{$\begin{array}{l}\text { People who are important to me would expect me to receive the } \\
\text { COVID-19 vaccine }\end{array}$} & $80 \%$ & $68 \%$ & $X^{2}=26.30$ & 0.0009 \\
\hline \multicolumn{3}{|c|}{$\begin{array}{l}\text { Most people who are important to me would think that I should } \\
\text { receive the COVID-19 vaccine }\end{array}$} & $81 \%$ & $67 \%$ & $X^{2}=40.31$ & 0.0001 \\
\hline \multicolumn{3}{|c|}{ Everyone I know would get the COVID-19 vaccine } & $57 \%$ & $49 \%$ & $X^{2}=15.07$ & 0.017 \\
\hline \multicolumn{3}{|c|}{ I would feel under social pressure to receive a COVID-19 vaccine } & $49 \%$ & $39 \%$ & $X^{2}=41.47$ & $<0.0001$ \\
\hline & Mean score (SD) overall & $\begin{array}{l}\text { Scale alpha } \\
\text { (standard- } \\
\text { ized) }\end{array}$ & $\begin{array}{l}\text { Not living with HIV } \\
(\mathrm{n}=5519)\end{array}$ & $\begin{array}{l}\text { Living with HIV } \\
(\mathrm{n}=69)\end{array}$ & Test-statistic & $\mathrm{p}$ value \\
\hline $\begin{array}{l}\text { Indirect Social Norms } \\
\text { (range from }-10 \text { to } 10 \\
\text { with higher scores } \\
\text { indicating being more } \\
\text { influenced by indirect } \\
\text { social norms) }\end{array}$ & $22.0( \pm 12.0)$ & 0.892 & $22.1( \pm 11.9)$ & $18.1( \pm 15.2)$ & $\mathrm{W}=152,898$ & 0.065 \\
\hline Missing & $754(13.5 \%)$ & & $741(13.4 \%)$ & $13(18.8 \%)$ & & \\
\hline $\begin{array}{l}\text { Indirect Social Norms: } \\
\text { Family Doctor/Primary } \\
\text { Healthcare Provider }\end{array}$ & $5.9( \pm 3.6)$ & & $5.9( \pm 3.6)$ & $5.2( \pm 4.6)$ & $\mathrm{W}=151,051$ & 0.52 \\
\hline $\begin{array}{l}\text { Indirect Social Norms: BC } \\
\text { Provincial Health Officer }\end{array}$ & $6.6( \pm 3.6)$ & & $6.6( \pm 3.6)$ & $5.1( \pm 4.0)$ & $\mathrm{W}=168,755$ & 0.004 \\
\hline
\end{tabular}


Table 4 (continued)

\begin{tabular}{llllll}
\hline & Mean score (SD) overall & $\begin{array}{l}\text { Scale alpha } \\
(\text { standard- } \\
\text { ized })\end{array}$ & $\begin{array}{l}\text { Not living with HIV } \\
(\mathrm{n}=5519)\end{array}$ & $\begin{array}{l}\text { Living with HIV } \\
(\mathrm{n}=69)\end{array}$ & Test-statistic $\mathrm{p}$ value \\
\hline $\begin{array}{l}\text { Indirect Social Norms: } \\
\text { Friends }\end{array}$ & $4.1( \pm 3.3)$ & $4.1( \pm 3.3)$ & $3.1( \pm 4.0)$ & $\mathrm{W}=168,559 \quad \mathbf{0 . 0 2 3}$ \\
$\begin{array}{l}\text { Indirect Social Norms: } \\
\text { Family }\end{array}$ & $5.4( \pm 3.7)$ & $5.4( \pm 3.7)$ & $4.2( \pm 4.7)$ & $\mathrm{W}=166,096 \quad \mathbf{0 . 0 5}$ \\
\hline
\end{tabular}

Bold values indicate the $p$-value is $<0.05$ and the result is statistically significant

wanted to, with no overall differences in the scale score by HIV status $(W=133,702 ; \mathrm{p}=0.19)$.

Overall, participants were influenced by direct social norms to receive a COVID-19 vaccine. A large majority agreed that people who are important to them would expect them to receive the COVID-19 vaccine and think that they should receive the COVID-19 vaccine. Agreement for the other two scale items was lower, including "Everyone I know would get the COVID-19 vaccine" and feeling "under social pressure to receive the COVID-19 vaccine". Participants LWH were significantly less likely to be influenced by direct social norms to receive the COVID-19 vaccine than those not LWH (mean score: 12.7 vs 14.7, respectively; $W=176,932 ; \mathrm{p}<0.0001)$.

Participants were similarly likely to report being influenced by indirect social norms overall, however, participants LWH were significantly less likely to be influenced by the BC Provincial Health Officer (the senior public health official directing the COVID-19 public health response), friends, or family. They were equally likely as participants not LWH to report being influenced by their family doctor/ primary healthcare provider (PHCP). Among participants LWH, the mean total Indirect Social Norms score was 18.1 $(\mathrm{SD}=15.2)$ compared with $22.1(\mathrm{SD}=11.9)$ among those not LWH $(W=152,898 ; \mathrm{p}=0.065)$.

\section{Predictors of Intention to Vaccinate Among Participants Living with HIV}

All the psychological constructs were significantly associated with vaccine intention in the overall sample, as expected and as previously shown [20] (all p-values $<0.001$ ) (Supplementary Table I).

Participants LWH who had a higher odds of reporting an intention to vaccinate were older (OR 1.05 per year increase; 95\% CI 1.00-1.10), reported one or more chronic health conditions (OR 3.50; 95\% CI 0.98-13.43), were less likely to lack vaccine confidence $(0.40$; $95 \%$ CI $0.18-0.71)$ more positive attitudes towards the COVID-19 vaccine (OR 1.31; 95\% CI 1.15-1.54), greater influence of direct social norms (OR 1.27 ; 95\% CI 1.08-1.54), and greater influence of indirect social norms from family doctors/PHCPs (OR 1.31; $95 \%$
CI 1.13-1.55), the BC provincial health officer (OR 1.74; 95\%CI 1.36-2.48), friends (OR 1.58; 95\% CI 1.25-2.20), and family (OR 1.65; 95\%CI 1.32-2.25). There was no statistically significant association between intention to vaccinate and perceived vaccine risks, perceived behavioral control, other assessed socio-demographic variables (ethnicity, education, household income, essential worker status), or perceived risk of acquiring COVID-19 due to HIV status. Owing to missing data and small cell sizes, we were not able to assess associations with HIV clinical variables (ART use, undetectable viral load) (Table 5).

Vaccine confidence demonstrated the largest effect, whereby participants LWH who expressed vaccine confidence had 2.5 fold higher odds of vaccine intention compared with those who lacked vaccine confidence. Given the small sample size and high degree of correlation between psychological constructs, adjusted analyses were not performed.

\section{Discussion}

In this large population-based sample of women and gender diverse individuals in $\mathrm{BC}$, we found that only two-thirds (65.2\%) of participants living with HIV (LWH) reported intending to receive a COVID-19 vaccine if recommended and available to them, significantly lower than participants not LWH (79.6\%). HIV status itself, however, was not significantly associated with COVID-19 vaccine intention in adjusted analyses. This finding is illustrative of the wide gap between the strong recommendations for COVID-19 vaccination for all PLWH and current intentions $[5,11,15]$. Findings are further concerning given the large proportion of participants LWH who belong to other communities prioritized for vaccine receipt due to higher risk of COVID-19 infection and severe illness, including those experiencing social inequities and co-morbidities.

The observed effect of HIV status on vaccine intention in unadjusted analyses was explained by differences in the distribution of other key socio-demographic factors, including Indigenous ancestry, being racialized, lower household income, lower education, and essential worker (non-health 
Table 5 Bivariable associations between socio-demographic, vaccine hesitancy, and psychological constructs and intention to receive the COVID19 vaccine among women and gender diverse individuals living with HIV $(n=69)$

\begin{tabular}{|c|c|c|c|}
\hline & Crude OR & $95 \% \mathrm{CI}$ & $\mathrm{p}$ value \\
\hline Age (per year increase) & 1.05 & $1.00-1.10$ & 0.048 \\
\hline \multicolumn{4}{|l|}{ Indigenous ancestry } \\
\hline No & Ref & Ref & \\
\hline Yes & 0.38 & $0.12-1.19$ & 0.10 \\
\hline \multicolumn{4}{|l|}{ Racialized } \\
\hline No (White) & Ref & Ref & \\
\hline Yes (Indigenous, African/Caribbean/Black, Other/mixed ethnicity) & 0.63 & $0.20-2.03$ & 0.43 \\
\hline \multicolumn{4}{|l|}{ Education } \\
\hline More than High School & Ref & Ref & \\
\hline High School or less & 0.40 & $0.14-1.13$ & 0.09 \\
\hline \multicolumn{4}{|l|}{ Household income } \\
\hline$\$ 20 \mathrm{~K}+$ per year & Ref & Ref & \\
\hline$<\$ 20 \mathrm{~K}$ per year & 0.43 & $0.11-1.62$ & 0.21 \\
\hline Don't know/no answer & 0.71 & $0.15-3.93$ & 0.68 \\
\hline \multicolumn{4}{|l|}{ Chronic health conditions } \\
\hline None & Ref & Ref & \\
\hline 1 or more & 3.50 & $0.98-13.4$ & 0.05 \\
\hline \multicolumn{4}{|l|}{ Essential worker } \\
\hline No & Ref & Ref & \\
\hline Yes, health worker & 0.44 & $0.07-2.62$ & 0.35 \\
\hline Yes, other essential worker & 0.71 & $0.20-2.66$ & 0.59 \\
\hline WHO Lack of Vaccine Confidence Scale & 0.40 & $0.18-0.71$ & 0.007 \\
\hline WHO Vaccine Risks Scale & 0.69 & $0.41-1.11$ & 0.141 \\
\hline Attitudes toward the COVID-19 Vaccine Scale & 1.31 & $1.15-1.54$ & $<0.001$ \\
\hline Perceived Behavioral Control Scale & 1.23 & $1.00-1.53$ & 0.058 \\
\hline Direct Social Norms Scale & 1.27 & $1.08-1.54$ & 0.007 \\
\hline Indirect Social Norms: Total Scale & 1.16 & $1.09-1.28$ & $<0.001$ \\
\hline Indirect Social Norms: Family Doctor/Primary Healthcare Provider & 1.31 & $1.13-1.55$ & 0.001 \\
\hline Indirect Social Norms: BC Provincial Health Officer & 1.74 & $1.36-2.48$ & $<0.001$ \\
\hline Indirect Social Norms: Friends & 1.58 & $1.25-2.20$ & 0.001 \\
\hline Indirect Social Norms: Family & 1.65 & $1.32-2.25$ & $<0.001$ \\
\hline
\end{tabular}

Bold values indicate the $p$-value is $<0.05$ and the result is statistically significant related) status, all previously shown to be associated with vaccine intention in the general BC population [20]. These findings are consistent with research from two general population studies in the US which reported nearly $80 \%$ of participants overall were likely/somewhat likely to receive the COVID-19 vaccine, with significantly lower prevalence among racialized and lower socio-economic status participants [19, 40].

We also found significant differences in vaccine hesitancy and psychological constructs that shape vaccine intention and uptake behaviors by HIV status. Participants LWH reported lower vaccine confidence, less positive attitudes towards the COVID-19 vaccine, and were less likely to be influenced by direct or indirect social norms to receive the COVID-19 vaccine. These findings are consistent with findings from a US study of Black Americans living with HIV who reported widespread COVID-19 mistrust, with over half reporting COVID-19 vaccine hesitancy [18].

Findings further suggest that efforts to address vaccine confidence and the psychological constructs measured using the Theory of Planned Behavior are important for supporting vaccine intention and uptake. Among participants LWH, we found that differences in the social determinants of health did not predict vaccine intentions. Rather, those with higher vaccine confidence, positive attitudes toward the COVID19 vaccine, and those who were more strongly influenced by direct and indirect social norms had significantly higher odds of reporting vaccine intention. Collectively, these data suggest that targeted and consistent messaging from family doctors/PHCPs and senior public health officials stating that COVID-19 vaccines are safe, effective, beneficial, and strongly recommended for PLWH, may be a pathway to improve vaccine confidence and attitudes. Specific 
information relevant for PLWH includes data regarding the immunogenicity and safety of COVID-19 vaccines among PLWH [41] and the importance of maintaining engagement in HIV care and adhering to ART even among those who are vaccinated. For reproductive-aged WLWH seeking to conceive, evidence regarding the safety and effectiveness of COVID-19 vaccines during pregnancy and breastfeeding will be further reassuring [42]. The opportunity for HIV care provider-led discussions is particularly relevant given that a majority of PLWH are engaged in HIV medical care and over half expressed being fearful that their HIV status would affect their risk of acquiring COVID-19. Research has shown that WLWH express high trust in their HIV care providers and identify them as the preferred source of relevant non-HIV specific information [43]. As we collectively move into the next "ground game" phase of increasing vaccine coverage, public health campaigns will need to support and foster these trusting relationships.

Efforts to support vaccine decision-making and uptake among PLWH can benefit from adopting community-based research principles of meaningful community involvement and engagement across the COVID-19 vaccine response $[44,45]$. Research with WLWH, has highlighted the profound influence that peers have on increasing knowledge and healthcare support for WLWH and these learnings should be extended to support informed vaccine decision-making and uptake of a COVID-19 vaccine.

The prevalence of vaccine intention over the course of data collection (August 2020-March 1, 2021) corresponds with a period of time during which the COVID-19 vaccine was not widely available in Canada [11]. In April 2021, vaccine eligibility expanded from priority groups to the general population, beginning with older individuals and extending to those aged $12+$ years by June 2021 [46]. As of July 26, $2021,81 \%$ of BC residents aged $12+$ years were partially vaccinated while $62 \%$ were fully vaccinated [47]. This firstdose vaccine uptake rate is highly consistent with our estimate of $79.7 \%$ of adults reporting vaccine intention. While no provincial estimates are yet available for PLWH, these data provide external validity to our findings.

\section{Limitations}

Although the number of participants LWH was small, the proportion of those LWH in this sample was higher than expected through general population-based recruitment strategies [48], enabling comparisons with the general population. Participants LWH in this analysis are comparable to the population of women living with HIV in BC by age and ethnicity, however reported higher education and household income relative to the general population of women living with HIV in BC [30, 48]. We did not have sufficient sample size to conduct separate analyses for women and gender diverse individuals LWH. However, in bivariable analyses we did not observe significant differences in vaccine intention by gender, which further informed our decision to include both women and gender diverse individuals in analyses. The study sample was drawn from individuals who were sufficiently concerned about COVID-19, reasonably trusting of scientific research, and with sufficient resources (technological, time) to complete the online survey. Thus, our findings may over-estimate the true prevalence of vaccine intention.

\section{Conclusion}

Among a sample of women and gender diverse individuals, we found important disparities in vaccine intentions by HIV status. Vaccine intentions are, however, dynamic and may evolve as vaccine delivery programs expand. Ongoing efforts must ensure that people living with HIV, and other historically marginalized populations, continue to have equitable access to vaccines and up-to-date vaccine information. Such efforts must acknowledge that the same socio-structural inequities and injustices that produce HIV risk and consequence for women and gender diverse people undermine vaccine confidence and fuel COVID-19 inequities. Our findings suggest pathways for building vaccine confidence, address vaccine concerns, and support informed vaccination decision-making. In partnership with communities, such pathways can be leveraged to promote COVID-19 vaccine uptake among women and gender diverse people living with HIV.

Supplementary Information The online version contains supplementary material available at https://doi.org/10.1007/s10461-022-03577-w.

Acknowledgements The RESPPONSE Research Team would like to thank our participants for their contributions to this study. We also thank the Peer Research Associates Peggy Frank, Melanie Lee, and Valerie Nicholson who assisted with the recruitment of women living with HIV. We are grateful to Falla Jin, Emily Politeski, and Amber Campbell for their contributions to the study.

Author Contributions AK: (1) Conceptualization, (2) Data curation, (3) Formal analysis, (4) Funding acquisition, (5) Investigation, (6) Methodology, (7) Project administration, (8) Resources, (9) Supervision, (10) Visualization, (11) Writing-original draft, (12) Writingreview \& editing. LAB: (1) Conceptualization, (2) Data curation, (3) Funding acquisition, (4) Investigation, (5) Methodology, (6) Project administration, (7) Resources, (8) Supervision, (9) Writing-review \& editing. MCMM: (1) Methodology, (2) Writing—review \& editing. HCFC: (1) Methodology, (2) Writing-review \& editing. AYA: (1) Conceptualization, (2) Data curation, (3) Formal analysis, (4) Funding acquisition, (5) Methodology, (6) Visualization, (7) Writing-review \& editing. VN: (1) Methodology, (2) Writing—review \& editing. RG: (1) Methodology, (2) Project administration, (3) Supervision, (4) Writing-review \& editing. SG: (1) Methodology, (2) Project administration, (3) Writing—review \& editing. AB: (1) Project administration, 
(2) Software, (3) Supervision, (4) Writing - review \& editing. LWS: (1) Conceptualization, (2) Methodology, (3) Project administration, (4) Writing-review \& editing. AB: (1) Project administration, (2) Writing-review \& editing. LAMG: (1) Conceptualization, (2) Investigation, (3) Methodology, (4) Supervision, (5) Writing—review \& editing. MS: (1) Conceptualization, (2) Methodology, (3) Writing-review \& editing. GSO: (1) Conceptualization, (2) Data curation, (3) Funding acquisition, (4) Investigation, (5) Methodology, (6) Project administration, (7) Resources, (8) Supervision, (9) Writing—review \& editing. All authors contributed to the writing of the article, read, and approved the final manuscript for submission.

Funding Funding for this project was from a Michael Smith Foundation for Health Research Grant (19055) and a BC Women's Health Foundation Grant (LRZ30421) both awarded to Dr Lori Brotto and Dr. Gina S. Ogilvie. Additional support was provided by Simon Fraser University's Community-Engaged Research Initiative (CERi) awarded to Dr. Angela Kaida.

Data Availability Data cannot be shared publicly because of ethical restrictions. Data are available from the the UBC Research Ethics Board (contact via cwreb@bcchr.ubc.ca) for researchers who meet the criteria for access to confidential data.

Code Availability $\mathrm{R}$ code available on reasonable request to the corresponding author.

\section{Declarations}

Conflict of interest The authors declare that they have no competing interests.

Ethical Approval Ethical approval was received from The University of British Columbia Research Ethics Board (H20-01421). All methods performed as a part of this study were in accordance with the UBC Research Ethics Board guidelines.

Consent to Participate Informed consent to participate was obtained from participants.

Consent for Publication Not applicable.

\section{References}

1. Government of Canada. COVID-19 daily epidemiology update 2021 [Available from: https://health-infobase.canada.ca/covid-19/ epidemiological-summary-covid-19-cases.html\#a7. Accessed 10 July 2021.

2. Sundaram ME, Calzavara A, Mishra S, Kustra R, Chan AK, Hamilton MA, et al. Individual and social determinants of SARSCoV-2 testing and positivity in Ontario, Canada: a populationwide study. CMAJ. 2021;193(20):E723-34.

3. McKenzie K. Socio-demographic data collection and equity in covid-19 in Toronto. EClinicalMedicine. 2021;34:100812.

4. Morgan R, Baker P, Griffith DM, Klein SL, Logie CH, Mwiine AA, et al. Beyond a zero-sum game: how does the impact of COVID-19 vary by gender? Front Sociol. 2021. https://doi.org/ $10.3389 /$ fsoc. 2021.650729 .

5. Centers for Disease Control and Prevention (CDC). What to know about HIV and COVID-19 2021. https://www.cdc.gov/coron avirus/2019-ncov/need-extra-precautions/hiv.html. Accessed 1 March 2021.

6. Bhaskaran K, Rentsch CT, MacKenna B, Schultze A, Mehrkar A, Bates CJ, et al. HIV infection and COVID-19 death: a population-based cohort analysis of UK primary care data and linked national death registrations within the OpenSAFELY platform. Lancet HIV. 2021;8(1):e24-32.

7. Hadi YB, Naqvi SFZ, Kupec JT, Sarwari AR. Characteristics and outcomes of COVID-19 in patients with HIV: a multicentre research network study. AIDS. 2020;34(13):F3-8.

8. Miyashita H, Kuno T. Prognosis of coronavirus disease 2019 (COVID-19) in patients with HIV infection in New York City. HIV Med. 2021;22(1):e1-2.

9. Brown LB, Spinelli MA, Gandhi M. The interplay between HIV and COVID-19: summary of the data and responses to date. Curr Opin HIV AIDS. 2021;16(1):63-73.

10. Collins LF. Persons with human immunodeficiency virus and the coronavirus disease 2019 pandemic: a viral synergy of biology and sociology. Clin Infect Dis. 2020;73:e2106.

11. National Advisory Committee on Immunization (NACI). Recommendations on the use of COVID-19 vaccines [Internet]. 2021. https://www.canada.ca/en/public-health/services/immun ization/national-advisory-committee-on-immunization-naci/ recommendations-use-covid-19-vaccines.html. Accessed 1 March 2021.

12. Government of Canada. Canada's COVID-19 Immunization Plan: Saving Lives and Livelihoods [Internet]. 2020. https://www.canada.ca/content/dam/phac-aspc/documents/services/diseases/2019novel-coronavirus-infection/canadas-reponse/canadas-covid-19immunization-plan-en.pdf. Accessed 1 March 2021.

13. Pebody R. Have COVID-19 vaccines been tested in people with HIV? 2021. https://www.aidsmap.com/about-hiv/have-covid-19vaccines-been-tested-people-hiv. Accessed 1 May 2021.

14. Burns F. HIV and COVID-19 vaccines. International Workshop on HIV and Women; Virtual. https://academicmedicaleducation. com/hiv-women-2021. Accessed 26 April 2021.

15. BC Centre for Excellence in HIV/AIDS (BCCfE). CDET Committee Statement Update on the use of COVID-19 vaccines in persons living with HIV May 7 2021. http://bccfe.ca/sites/defau 1t/files/uploads/publications/centredocs/covid-19_vaccine_cdet_ update_final_5_pm_2021_may_9th_.pdf. Accessed 1 June 2021.

16. MacDonald NE. Vaccine hesitancy: definition, scope and determinants. Vaccine. 2015;33(34):4161-4.

17. World Health Organization (WHO). Report of the SAGE working group on vaccine hesitancy (October 2014). 2014. https://www. who.int/immunization/sage/meetings/2014/october/1_Report_ WORKING_GROUP_vaccine_hesitancy_final.pdf. Accessed 1 March 2021.

18. Bogart LM, Ojikutu BO, Tyagi K, Klein DJ, Mutchler MG, Dong L, et al. COVID-19 related medical mistrust, health impacts, and potential vaccine hesitancy among black Americans living with HIV. J Acquir Immune Defic Syndr. 2021;86(2):200-7.

19. Grumbach K, Judson T, Desai M, Jain V, Lindan C, Doernberg SB, et al. Association of race/ethnicity with likeliness of COVID-19 vaccine uptake among health workers and the general population in the San Francisco Bay Area. JAMA Intern Med. 2021;181(7):1008-11.

20. Ogilvie GS, Gordon S, Smith LW, Albert A, Racey CS, Booth A, et al. Intention to receive a COVID-19 vaccine: results from a population-based survey in Canada. BMC Public Health. 2021;21(1):1017.

21. Vallée A, Fourn E, Majerholc C, Touche P, Zucman D. COVID-19 vaccine hesitancy among French people living with HIV. Vaccines. 2021;9(4):302. 
22. Bourgeois AC, Edmunds M, Awan A, Jonah L, Varsaneux O, Siu W. HIV in Canada-Surveillance Report, 2016. Can Commun Dis Rep. 2017;43(12):248-56.

23. Shokoohi M, Bauer GR, Kaida A, Lacombe-Duncan A, Kazemi M, Gagnier B, et al. Social determinants of health and self-rated health status: a comparison between women with HIV and women without HIV from the general population in Canada. PLoS ONE. 2019;14(3):e0213901.

24. Donaldson MA, Campbell AR, Albert AY, Borhani M, Nesbitt A, Côté HCF, et al. Comorbidity and polypharmacy among women living with HIV in British Columbia. AIDS. 2019;33(15):2317-26

25. Kendall CE, Wong J, Taljaard M, Glazier RH, Hogg W, Younger J, et al. A cross-sectional, population-based study measuring comorbidity among people living with HIV in Ontario. BMC Public Health. 2014;14(1):161

26. Lourenço L, Colley G, Nosyk B, Shopin D, Montaner JS, Lima VD. High levels of heterogeneity in the HIV cascade of care across different population subgroups in British Columbia, Canada. PLoS ONE. 2014;9(12):e115277.

27. Shapiro GK, Tatar O, Dube E, Amsel R, Knauper B, Naz A, et al. The vaccine hesitancy scale: psychometric properties and validation. Vaccine. 2018;36(5):660-7.

28. Ajzen I. The theory of planned behavior. Organ Behav Hum Decis Process. 1991;50(2):179-211.

29. Women's Health Research Institute (WHRI). RESPPONSE: Rapid Evidence Study of a Provincial Population Based COhort for GeNder and SEx. 2020. https://whri.org/covid-19-respponsestudy/. Accessed 1 Feb 2021.

30. Loutfy M, de Pokomandy A, Kennedy VL, Carter A, O'Brien N, Proulx-Boucher K, et al. Cohort profile: The Canadian HIV Women's Sexual and Reproductive Health Cohort Study (CHIWOS). PLoS ONE. 2017;12(9):e0184708.

31. Loutfy MR, Sherr L, Sonnenberg-Schwan U, Walmsley SL, Johnson M, d'Arminio Monforte A, et al. Caring for women living with HIV: gaps in the evidence. J Int AIDS Soc. 2013;16(1):18509.

32. Hankins C. Gender, sex, and HIV: how well are we addressing the imbalance? Curr Opin HIV AIDS. 2008;3(4):514-20.

33. Webster K, Carter A, Proulx-Boucher K, Dubuc D, Nicholson $\mathrm{V}$, Beaver K, et al. Strategies for recruiting women living with human immunodeficiency virus in community-based research: lessons from Canada. Prog Community Health Partnersh. 2018;12(1):21-34.

34. Canadian Institutes of Health Research (CIHR). Strategy for patient-oriented research—patient engagement framework 2019. https://cihr-irsc.gc.ca/e/48413.html. Accessed 1 March 2021.

35. Kaida A, Carter A, Nicholson V, Lemay J, O’Brien N, Greene $\mathrm{S}$, et al. Hiring, training, and supporting Peer Research Associates: operationalizing community-based research principles within epidemiological studies by, wtih, and for women living with HIV. Harm Reduct J. 2019;16:8. https://doi.org/10.1186/ s12954-019-0309-3.

36. Harris PA, Taylor R, Thielke R, Payne J, Gonzalez N, Conde JG. Research electronic data capture (REDCap)-a metadatadriven methodology and workflow process for providing translational research informatics support. J Biomed Inform. 2009;42(2):377-81.
37. Statistics Canada. Ethnic Origin Reference Guide, Census of Population, 2016. 2017. https://www12.statcan.gc.ca/censusrecensement/2016/ref/guides/008/98-500-x2016008-eng.cfm. Accessed 1 July 2020.

38. Government of British Columbia. COVID-19 List of Essential Services 2020. https://www2.gov.bc.ca/assets/gov/family-andsocial-supports/covid-19/list_of_essential_services.pdf. Accessed 1 July 2020.

39. $\mathrm{R}$ Core Team. The R Project for Statistical Computing v.4.0.2. 2020. https://www.r-project.org/. Accessed 16 Nov 2020.

40. Khubchandani J, Sharma S, Price JH, Wiblishauser MJ, Sharma M, Webb FJ. COVID-19 vaccination hesitancy in the United States: a rapid national assessment. J Community Health. 2021;46(2):270-7.

41. Frater J, Ewer KJ, Ogbe A, Pace M, Adele S, Adland E, et al. Safety and immunogenicity of the ChAdOx $1 \mathrm{nCoV}-19$ (AZD1222) vaccine against SARS-CoV-2 in HIV infection: a single-arm substudy of a phase $2 / 3$ clinical trial. Lancet HIV. 2021;8:e474.

42. Shimabukuro TT, Kim SY, Myers TR, Moro PL, Oduyebo T, Panagiotakopoulos L, et al. Preliminary findings of mRNA Covid-19 vaccine safety in pregnant persons. N Engl J Med. 2021;384(24):2273-82.

43. Patterson S, Nicholson V, Milloy MJ, Ogilvie G, Hogg RS, Carter A, et al. Awareness and understanding of HIV non-disclosure case law and the role of healthcare providers in discussions about the criminalization of HIV non-disclosure among women living with HIV in Canada. AIDS Behav. 2020;24(1):95-113.

44. Kaida A, Carter A, Nicholson V, Lemay J, O’Brien N, Greene $\mathrm{S}$, et al. Hiring, training, and supporting Peer Research Associates: operationalizing community-based research principles within epidemiological studies by, with, and for women living with HIV. Harm Reduct J. 2019;16(1):47.

45. Loutfy M, Greene S, Kennedy VL, Lewis J, Thomas-Pavanel J, Conway T, et al. Establishing the Canadian HIV Women's Sexual and Reproductive Health Cohort Study (CHIWOS): operationalizing community-based research in a large national quantitative study. BMC Med Res Methodol. 2016;16(1):101.

46. Government of British Columbia. COVID-19 Immunization Plan. 2020. https://www2.gov.bc.ca//gov/content/covid-19/vaccine/ plan. Accessed 1 June 2021.

47. Government of British Columbia. British Columbia COVID-19 dashboard. 2021. https://experience.arcgis.com/experience/a6f 23 959a8b14bfa989e3cda29297ded. Accessed 8 July 2021.

48. BC Centre for Disease Control (BCCDC). HIV in British Columbia: Annual Surveillance Report 2017. 2019. http://www.bccdc. ca/health-professionals/data-reports/hiv-aids-reports. Accessed 1 June 2021

Publisher's Note Springer Nature remains neutral with regard to jurisdictional claims in published maps and institutional affiliations. 